\title{
Hydration, dehydration, underhydration, optimal hydration: are we barking up the wrong tree?
}

\author{
Stavros A. Kavouras ${ }^{1,2}$ \\ Published online: 3 January 2019 \\ ○) Springer-Verlag GmbH Germany, part of Springer Nature 2019
}

\section{Dear Editor,}

According to the Medical Subject Headings of the US National library of medicine "dehydration is the condition that results from excessive loss of water from a living organism" [1]. Even though dehydration describes the state of body water deficit, some scientists have suggested that dehydration refers to the process of losing water, while hypohydration is the state of water deficit, and rehydration is the process of gaining water from a hypohydrated state towards euhydration [2].

To define dehydration or hypohydration in a laboratory setting, scientists have been using acute changes of body weight as the gold standard [3]. For instance, if someone weighs $70 \mathrm{~kg}$ in a euhydrated state, the acute loss of $-1.4 \mathrm{~kg}$ is equivalent to dehydration of $-2 \%$ of body weight $(-1.4 \mathrm{~kg} / 70 \mathrm{~kg} \times 100 \%)$. Unfortunately, outside of laboratories where experimentally-induced dehydration is controlled, we rarely have a recent baseline euhydrated body weight to be able to accurately examine the presence and the degree of water deficit. For this reason, different blood, urine, and clinical biomarkers have been used to assess hydration status [4].

The majority of research on water homeostasis and its effects on the human body has focused on how water deficit impacts exercise performance, mainly in hot environments [5]. Edward Adolf in his classic work "Physiology of Man in the Desert" was one of the first to study the effect of water intake on thermoregulation and performance [6]. He also introduced the term voluntary dehydration when he

Stavros A. Kavouras

stavros.kavouras@asu.edu

1 Hydration Science Lab, College of Health Solutions, Arizona State University, Arizona Biomedical Collaborate, Suite 133, 435 N 5th St, Phoenix, AZ 85004, USA

2 Division of Endocrinology, University of Arkansas for Medical Sciences, Little Rock, AR, USA observed that during "rapid sweating", humans do not drink enough to maintain body water. He concluded that: “... when he is active and needs much water his thirst sensations are inadequate". During the last 30 years we have learned that even a mild degree of dehydration $(<2 \%$ of body weight) can impair exercise performance and increase heat strain, especially in the heat $[5,7]$. The degree of exercise-induced dehydration often ranges between 2 and $5 \%$ of body weight and it is accompanied by elevated plasma osmolality, decreased plasma volume, and increased urinary biomarkers (i.e. urine osmolality) [5]. Influenced by this observation and based on the mathematical symmetric property stating that if $\mathrm{A}=\mathrm{B}$, then $\mathrm{B}=\mathrm{A}$, we have mistakenly assumed that the backward association is also true. Thus, if exerciseinduced dehydration leads to increased urine biomarkers, then elevated urinary biomarkers should correspond with water deficit and dehydration. So, when we read data indicating that a majority of children, adults, and athletes have elevated levels of urinary osmolality or specific gravity we mistakenly conclude that a large portion of the population is dehydrated [8-11]. Furthermore, when we read data indicating that a majority of people across the world do not meet the dietary guidelines for water intake we also conclude that most people are dehydrated. Is it possible that people with free access to water when they do not meet the water intake guidelines or when they have elevated urinary biomarkers are dehydrated? Probably not.

Let's examine the data from the National Health and Nutrition Examination Survey (NHANES) in the US. If we compare the 10th $(1694 \mathrm{~mL} /$ day $)$ and the 90th $(7934 \mathrm{~mL} /$ day) percentile of water intake distribution in the US we will notice that they have nearly identical plasma osmolality (279 and $280 \mathrm{mmol} / \mathrm{kg}$, respectively) [12]. Similarly, people who chronically consume either low (low-drinkers) or high (high-drinkers) amounts of water have similar plasma osmolality, but low-drinkers have greater vasopressin [13]. In 2015, Johnson and his colleagues published a study that identified low- and high-drinkers through an initial screening 
[14]. Then, they converted the low-drinkers to high-drinkers by increasing their water intake and the high-drinkers to low-drinkers by decreasing their water intake. Interestingly, body weight and plasma osmolality remained unaffected by the change in water intake in both groups. Nevertheless, urine volume and urine osmolality changed remarkably in both groups due to the intervention. These data suggest that drinking more or less water impacts the levels of vasopres$\sin$ (AVP) as well as the volume and concentration of urinary output but does not affect total body water. How is this possible? Our water homeostasis is mainly regulated by the hormone vasopressin and thirst. AVP is very quickly activated by a slight water deficit and induces nearly maximal renal water conservation in low plasma concentrations well before activation of thirst [15]. Moreover, during dehydration, thirst sensation can be quickly terminated prior to full water restoration (rehydration) as a response to the act of swallowing via activation of the oropharyngeal receptors' [16]. In that case, we could be in a state of elevated AVP even in the absence of thirst. The important question: is low water intake, in the absence of dehydration, associated with negative health or performance outcomes.

Epidemiological data indicate that low water intake or elevated hydration biomarkers are associated with several adverse health outcomes [17]. Low water intake and elevated AVP, assessed by its surrogate marker copeptin, is linked to chronic kidney disease and diabetes [18, 19]. Also, increased water intake, even in patients with third stage chronic kidney disease, is well tolerated and suppresses high copeptin levels [20]. Drinking more water has also been found to dramatically decrease the recurrence of urinary tract infections [21], and to improve glucose regulation in people with low water intake or elevated copeptin [22]. Additionally, children with very concentrated urine (an indication of high AVP) can improve cognitive [23] and endurance performance [24] by drinking more water. These data suggest that low water intake is associated with negative health and performance outcomes.

Therefore, low water intake or chronically elevated urinary biomarkers does not mean by default dehydration, since total body water is maintained, and blood osmolality is typically unaffected. In the literature, scientists have referred to the hydration state of elevated urinary hydration biomarkers as either mild-dehydration, insufficient hydration, suboptimal hydration, or pre-dehydration [11, 25, 26]. Instead, I propose the term underhydration that may better capture the nature of this phenomenon, encompassing low water intake (consuming less than the reference values), in the absence of total body water deficit, thirst or elevated plasma osmolality, while the water homeostatic mechanism has been activated as indicated by elevated vasopressin and urine biomarkers (Fig. 1). It is time to differentiate the term dehydration from underhydration and refrain from using dehydration when

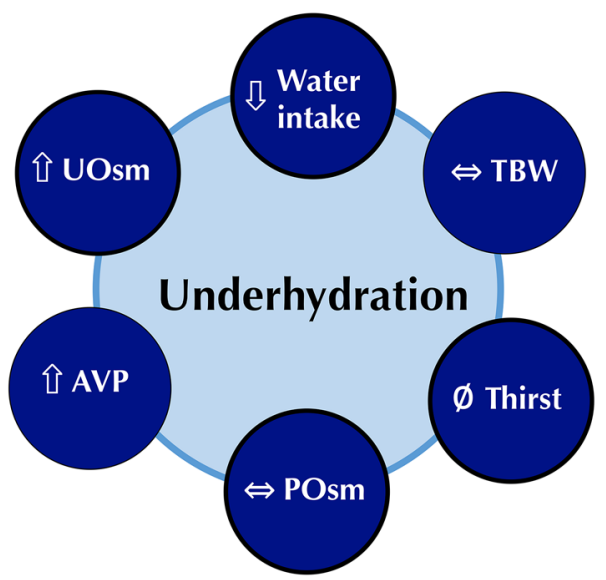

Fig. 1 Characteristics of state of underhydration. $T B \mathrm{~W}$ total body water, POsm plasma osmolality, AVP arginine vasopressin; UOsm, urine osmolality

someone only has elevated urine osmolality or does not meet the dietary water intake reference values.

Of course, the topic of hydration and health is new and under researched [27]. At this point, we probably have more questions than answers and theories on potential mechanisms associating low water intake with various unexplored pathologies, including cancer and longevity [28, 29]. However, it is time to concentrate our efforts on the health implications of being a low-drinker rather than examining the acute effects of dehydration (water deficit). We need large scale studies and randomized control trials to investigate how increased water intake impacts health and well-being.

Acknowledgements The author wishes to thank Abigail Colburn for her editorial support and the development of the figure; HyunGyu Suh, Adam Seal, and Lisa Jansen for countless discussion on the topic.

Funding The author has not received any funding for this review.

\section{Compliance with ethical standards}

Conflict of interest SAK has serve as scientific consultants for Quest Diagnostics, Standard Process, and Danone Research. SAK has received grants from Danone Research.

\section{References}

1. US National Library of Medicine (2018) Medical subject headings. https://meshb.nlm.nih.gov/record/ui?ui=D003681. Accessed 13 Dec 2018

2. Greenleaf JE (1992) Problem: thirst, drinking behavior, and involuntary dehydration. 24 (6):645-656

3. Armstrong LE (2007) Assessing hydration status: the elusive gold standard. J Am Coll Nutr 26(5 Suppl):575S-584S 
4. Armstrong LE, Kavouras SA, Walsh NP, Roberts WO (2016) Diagnosing dehydration? Blend evidence with clinical observations. Curr Opin Clin Nutr Metab Care 19(6):434-438

5. Cheuvront SN, Kenefick RW (2014) Dehydration: physiology, assessment, and performance effects. Compr Physiol 4(1):257-285

6. Adolph E, Associates (1969) Physiology of man in the desert. Hafner Publishing Company, New York

7. Adams JD, Sekiguchi Y, Suh H, Seal AD, Sprong CA, Kirkland TW, Kavouras SA (2018) Dehydration impairs cycling performance, independently of thirst: a blinded study. Med Sci Sports Exerc 50(8):1697-1703

8. Hew-Butler TD, Eskin C, Bickham J, Rusnak M, VanderMeulen M (2018) Dehydration is how you define it: comparison of 318 blood and urine athlete spot checks. BMJ Open Sport Exerc Med 4(1):e000297

9. Arnaoutis G, Kavouras SA, Kotsis YP, Tsekouras YE, Makrillos M, Bardis CN (2013) Ad libitum fluid intake does not prevent dehydration in suboptimally hydrated young soccer players during a training session of a summer camp. Int J Sport Nutr Exerc Metab 23(3):245-251

10. Osterberg KL, Horswill CA, Baker LB (2009) Pregame urine specific gravity and fluid intake by National Basketball Association players during competition. J Athl Train 44(1):53-57

11. Kenney EL, Long MW, Cradock AL, Gortmaker SL (2015) Prevalence of Inadequate Hydration Among US Children and Disparities by Gender and Race/Ethnicity: National Health and Nutrition Examination Survey, 2009-2012. Am J Public Health 105(8):e113-e118

12. Panel on Dietary Reference Intakes for Electrolytes and Water. Food and Nutrition Board Institute of Medicine (2004) Dietary reference intakes for water, potassium, sodium, chloride, and sulfate. National Academy Press, Washington DC

13. Perrier E, Vergne S, Klein A, Poupin M, Rondeau P, Le Bellego L, Armstrong LE, Lang F, Stookey J, Tack I (2012) Hydration biomarkers in free-living adults with different levels of habitual fluid consumption. BJN 109(09):1-10

14. Johnson EC, Munoz CX, Le Bellego L, Klein A, Casa DJ, Maresh CM, Armstrong LE (2015) Markers of the hydration process during fluid volume modification in women with habitual high or low daily fluid intakes. Eur J Appl Physiol 115(5):1067-1074

15. Robertson GL (2012) Thirst and vasopressin. In: Alpern RJ, Caplan MJ, Moe OW (eds) Seldin and Giebisch's the kidney: physiology and pathophysiology. Elsevier Science \& Technology, ProQuest Ebook Central, Ann Arbor, MI
16. Figaro MK, Mack GW (1997) Regulation of fluid intake in dehydrated humans: role of oropharyngeal stimulation. Am J Physiol 272(6 Pt 2):R1740-R1746

17. Seal AD, Suh H, Jansen LT, Summers LG, Kavouras SA (2018) Hydration and health. In: Pounis G (ed) Analysis in nutrition research. Elsevier, London, pp 299-319

18. Clark WF, Sontrop JM, Huang S-H, Moist L, Bouby N, Bankir L (2016) Hydration and chronic kidney disease progression: a critical review of the evidence. Am J Nephrol 43(4):281-292

19. Enhörning S, Wang TJ, Nilsson PM, Almgren P, Hedblad B, Berglund G, Struck J, Morgenthaler NG, Bergmann A, Lindholm E, Groop L, Lyssenko V, Orho-Melander M, Newton-Cheh C, Melander O (2010) Plasma copeptin and the risk of diabetes mellitus. Circulation 121(19):2102-2108

20. Sontrop JM, Huang S-H, Garg AX, Moist L, House AA, Gallo K, Clark WF (2015) Effect of increased water intake on plasma copeptin in patients with chronic kidney disease: results from a pilot randomised controlled trial. BMJ Open 5(11):e008634

21. Hooton TM, Vecchio M, Iroz A, Tack I (2018) Effect of increased daily water intake in premenopausal women with recurrent urinary tract infections: a randomized clinical trial. JAMA Intern Med 178(11):1509-1515

22. Enhörning S, Tasevska I, Roussel R, Bouby N, Persson M, Burri P, Bankir L, Melander O (2017) Effects of hydration on plasma copeptin, glycemia and gluco-regulatory hormones: a water intervention in humans. Eur J Nutr 176:893

23. Fadda R, Rapinett G, Grathwohl D, Parisi M, Fanari R, Calò CM, Schmitt J (2012) Effects of drinking supplementary water at school on cognitive performance in children. Appetite 59(3):730-737

24. Kavouras SA, Arnaoutis G, Makrillos M, Garagouni C, Nikolaou E, Chira O, Ellinikaki E, Sidossis LS (2012) Educational intervention on water intake improves hydration status and enhances exercise performance in athletic youth. Scand J Med Sci Sports 22(5):684-689

25. Popkin BM, D'Anci KE, Rosenberg IH (2010) Water, hydration, and health. Nutr Rev 68(8):439-458

26. Robertson GL (1974) Vasopressin in osmotic regulation in man. Annu Rev Med 25:315-322

27. Rush EC (2013) Water: neglected, unappreciated and under researched. Eur J Clin Nutr 67(5):492-495

28. Thornton SN (2011) Cancer, diabetes, and angiotensin blockade: a question of hypohydration. J Clin Oncol 29(33):4465-4466

29. Thornton SN (2011) Angiotensin inhibition and longevity: a question of hydration. Pflgers Arch Eur J Physiol 461(3):317-324 